Check for updates

Cite this: Chem. Sci., 2019, 10, 524

๑ All publication charges for this article have been paid for by the Royal Society of Chemistry

Received 27th August 2018 Accepted 15th October 2018

DOI: $10.1039 / \mathrm{c} 8 \mathrm{sc} 03816 \mathrm{c}$

rsc.li/chemical-science

\section{Three to tango requires a site-specific substitution: heterotrimetallic molecular precursors for high- voltage rechargeable batteries $\uparrow$}

\author{
Haixiang Han, (D) ${ }^{a}$ Zheng Wei, ${ }^{a}$ Alexander S. Filatov, ${ }^{b}$ Jesse C. Carozza, ${ }^{a}$ Melisa Alkan, ${ }^{c}$
} Andrey Yu. Rogachev, (D) Andrey Shevtsov, ${ }^{d}$ Artem M. Abakumov, ${ }^{d}$ Chongin Pak, $^{,}$ Michael Shatruk, ${ }^{e}$ Yu-Sheng Chen ${ }^{f}$ and Evgeny V. Dikarev (D) *a

Design of heterotrimetallic molecules, especially those containing at least two different metals with close atomic numbers, radii, and the same coordination number/environment is a challenging task. This quest is greatly facilitated by having a heterobimetallic parent molecule that features multiple metal sites with only some of those displaying substitutional flexibility. Recently, a unique heterobimetallic complex $\mathrm{LiMn}_{2}$ (thd) ${ }_{5}$ (thd $=$ 2,2,6,6-tetramethyl-3,5-heptanedionate) has been introduced as a single-source precursor for the preparation of a popular spinel cathode material, $\mathrm{LiMn}_{2} \mathrm{O}_{4}$. Theoretical calculations convincingly predict that in the above trinuclear molecule only one of the $\mathrm{Mn}$ sites is sufficiently flexible to be substituted with another $3 d$ transition metal. Following those predictions, two heterotrimetallic complexes, $\mathrm{LiMn}_{2-x} \mathrm{Co}_{x}(\mathrm{thd})_{5}(x=1$ (1a) and 0.5 (1b)), that represent full and partial substitution, respectively, of $\mathrm{Co}$ for $\mathrm{Mn}$ in the parent molecule, have been synthesized. X-ray structural elucidation clearly showed that only one transition metal position in the trinuclear molecule contains Co, while the other site remains fully occupied by $\mathrm{Mn}$. A number of techniques have been employed for deciphering the structure and composition of heterotrimetallic compounds. Synchrotron resonant diffraction experiments unambiguously assigned $3 \mathrm{~d}$ transition metal positions as well as provided a precise "sitespecific $\mathrm{Mn} / \mathrm{Co}$ elemental analysis" in a single crystal, even in an extremely difficult case of severely disordered structure formed by the superposition of two enantiomers. DART mass spectrometry and magnetic measurements clearly confirmed the presence of heterotrimetallic species $\mathrm{LiMnCo}_{\mathrm{M}}$ thd $)_{5}$ rather than a statistical mixture of two heterobimetallic $\mathrm{LiMn}_{2}(\mathrm{thd})_{5}$ and $\mathrm{LiCO}_{2}(\mathrm{thd})_{5}$ molecules. Heterometallic precursors $1 \mathrm{a}$ and $1 \mathrm{~b}$ were found to exhibit a clean decomposition yielding phase-pure $\mathrm{LiMnCoO}_{4}$ and $\mathrm{LiMn}_{1.5} \mathrm{CO}_{0.5} \mathrm{O}_{4}$ spinels, respectively, at the relatively low temperature of $400{ }^{\circ} \mathrm{C}$. The latter oxide represents an important " $5 \mathrm{~V}$ spinel" cathode material for the lithium ion batteries. Transmission electron microscopy confirmed a homogeneous distribution of transition metals in quaternary oxides obtained by pyrolysis of single-source precursors.

\footnotetext{
${ }^{a}$ Department of Chemistry, University at Albany, SUNY, Albany, NY, 12222, USA. E-mail: edikarev@albany.edu

${ }^{b}$ Department of Chemistry, University of Chicago, Chicago, IL, 60637, USA 'Department of Chemistry, Illinois Institute of Technology, Chicago, IL 60616, USA ${ }^{d}$ Skolkovo Institute of Science and Technology, Moscow 143026, Russia ${ }^{e}$ Department of Chemistry and Biochemistry, Florida State University, Tallahassee, FL 32306, USA

${ }^{f}$ NSF's ChemMatCARS, Center for Advanced Radiation Source, The University of Chicago, Argonne, IL 60439, USA

$\dagger$ Electronic supplementary information (ESI) available: Experimental procedures, synthetic details, X-ray powder diffraction analysis, IR and mass spectra, phase analysis of thermal decomposition traces of heterometallic precursor. CCDC 1844130 and 1844131. For ESI and crystallographic data in CIF or other electronic format see DOI: $10.1039 / \mathrm{c} 8 \mathrm{sc} 03816 \mathrm{c}$
}

\section{Introduction}

An insertion of additional 3d transition metals into the parent heterobimetallic assembly (conventionally known as doping or substitution method) to prepare heteromultimetallic compounds is widely recognized as an effective approach to better-performing energy-related materials..$^{1-4}$ One field that has especially benefited from application of this technique is the development of new rechargeable battery materials. ${ }^{5-8}$ It is believed that the most important factors with respect to the evaluation of a promising cathode material, such as capacity, reversibility, and working potential, are directly related to a synergy between transition metal constituents., ${ }^{5,9-12}$

The discovery of $\mathrm{LiMn}_{2} \mathrm{O}_{4}$ spinel oxide is one of the cornerstones in the exploration of new electrochemically-active materials. ${ }^{10,13-16}$ This positive electrode material has been 
widely adopted by the battery industry due to its good overall electrochemical performance, environmental friendliness, and low production costs. ${ }^{11,17}$ Research-wise, it provides the basis for continued scientific endeavours into the design of new spinel oxides with improved characteristics that can greatly expand their practical applications. ${ }^{7,18,19}$ A number of studies have demonstrated that Li-Mn spinels exhibit great flexibility in accommodating a variety of dopant metals, such as $\mathrm{Cr}, \mathrm{Fe}, \mathrm{Co}$, $\mathrm{Ni}$, and $\mathrm{Zn} .^{7,19-25}$ Among the wide range of these transition metal-doped spinel materials, the insertion of Co into the $\mathrm{LiMn}_{2} \mathrm{O}_{4}$ framework is particularly interesting. ${ }^{26,27} \mathrm{Based}$ on the $\mathrm{LiMn}_{2} \mathrm{O}_{4}$ archetype, $\left[\mathrm{LiMn}^{3+} \mathrm{Mn}^{4+} \mathrm{O}_{4}\right.$ ], the trivalent $\mathrm{Mn}^{3+}$ sites can be partially or fully substituted by the $\mathrm{Co}^{3+}$ cations yielding $\mathrm{LiMn}_{2-x} \mathrm{Co}_{x} \mathrm{O}_{4}$ spinels with $x \leq 1 .{ }^{28-30}$ Among the latter oxides with different $\mathrm{Mn} / \mathrm{Co}$ ratios, the $\mathrm{LiMn}_{1.5} \mathrm{Co}_{0.5} \mathrm{O}_{4}$ composition $(x$ $=0.5$ ) stands out as the most important with respect to the practical applications as a cathode material. ${ }^{31}$ It is known to exhibit the most balanced electrochemical properties, especially reversibility and energy density. ${ }^{26,27}$ Specifically, the addition of the $\mathrm{Co}^{4+} / \mathrm{Co}^{3+}$ redox couple endows $\mathrm{LiMn}_{1.5} \mathrm{Co}_{0.5} \mathrm{O}_{4}$ with a high working potential, rendering this oxide into an exclusive class of cathode materials: the so-called " $5 \mathrm{~V}$ spinels".,32-34

The preparation of quaternary oxides is known to suffer from several drawbacks. Formation of the thermodynamicallyfavoured binary and tertiary intermediates may result in irremovable impurities and/or nonstoichiometric products. ${ }^{20,35,36}$ On top of that comes an often-overlooked problem of homogeneous distribution of transition metals in the product oxide at the microstructural level. ${ }^{37-39}$ In the particular case of the Mnbased spinel compounds, the high-temperature preparation routes should be avoided. ${ }^{40-42}$ The elevated temperatures not only create difficulties in obtaining nanosize materials with regular morphology and a narrow range of the particle size distribution, ${ }^{43-45}$ but also can cause decomposition of spinel into a monoclinic $\mathrm{Li}_{2} \mathrm{MnO}_{3}$ phase ${ }^{46-48}$ Therefore, there is a great need for alternative synthetic approaches that allow one to avoid the above problems. One of the ways to overcome the difficulties in preparation of quaternary oxide materials is the use of molecular precursors that contain all necessary metals in the proper ratio and decompose at lower temperatures to yield phase-pure nanosize target materials. ${ }^{49-51}$ The intimate mixing of different metals within heterotrimetallic precursors ensures the homogeneity of metal distribution in the target products as well as facilitates a rapid interaction between the constituent elements of the molecule upon thermolysis to circumvent the formation of unwanted intermediates. ${ }^{52,53}$

Design of heterotrimetallic molecular precursors, especially those containing at least two different metal atoms with close atomic numbers, radii, and coordination preferences is not a trivial task. It is certainly helpful to have a model heterobimetallic parent molecule featuring multiple metal sites with only some of those displaying a substitutional flexibility. Several years ago, we introduced the first molecular single-source precursor for the spinel cathode material $\mathrm{LiMn}_{2} \mathrm{O}_{4}{ }^{51}$ The highly volatile and soluble trinuclear complex $\operatorname{LiMn}_{2}(\text { thd })_{5}$ (thd $=2,2,6,6$-tetramethyl-3,5-heptanedionate) has been shown to yield phase-pure $\mathrm{LiMn}_{2} \mathrm{O}_{4}$ spinel oxide upon thermal decomposition in the solid state/gas phase. Herein we report our strategy to utilize the parent structure of heterobimetallic Li-Mn diketonate as a model to design heterotrimetallic molecular precursors for the Co-containing oxides. While heterometallic compound with the $\mathrm{Li}: \mathrm{Mn}: \mathrm{Co}=1: 1: 1$ ratio (1a) was the focus of our quest into making a "true" heterotrimetallic molecule, the one with $1: 1.5: 0.5$ composition (1b) was the major target for future practical applications.

\section{Design of heterotrimetallic $\mathrm{Li}-\mathrm{Mn}-\mathrm{Co}$ precursor: structural and theoretical considerations}

In order to design a heterotrimetallic molecular precursor with the desired $\mathrm{Li}: \mathrm{Mn}:$ Co ratio of $1: 1: 1$, we chose the parent trinuclear structure of $\operatorname{LiMn}_{2}(\text { thd })_{5}$ (Scheme 1). Reported by us back in $2012,{ }^{51}$ this heterometallic molecule remains, to the best of our knowledge, the only structurally characterized molecular precursor for the $\mathrm{LiMn}_{2} \mathrm{O}_{4}$ spinel oxide material. As of today, we have been unable to replicate this trinuclear arrangement with other diketonate ligands or to obtain analogues with other divalent metals. In particular, the proposed isomorphous $\mathrm{LiCo}_{2}(\mathrm{thd})_{5}$ complex has not been isolated despite numerous attempts.

In the unique structure of $\operatorname{LiMn}_{2}(\text { thd })_{5},{ }^{51}$ five thd ligands act in chelating (2), chelating-bridging (1) and very unusual purely bridging (2) fashions. Such ligand arrangement ensures tetrahedral coordination for the $\mathrm{Li}$ center as well as a distorted octahedral environment for both Mn ions. An important note for further consideration is that the trinuclear molecule contains three chiral metal centres and features two enantiomers in the centrosymmetric crystal structure, namely $S$-Li, $\Delta$ Mn1, $\Lambda$-Mn2 (as shown in Scheme 1) and $R$-Li, $\Lambda$-Mn1, $\Delta-\mathrm{Mn} 2$. In addition, the ten bulky ${ }^{t} \mathrm{Bu}$ substituents on diketonate ligands are facing outward of the heterometallic assembly and provide a screening protection for the metal core from being oligomerized or involved in intermolecular interactions of any kind.

For the purpose of this research, the most important feature of the parent structure is the presence of two crystallographically independent $\mathrm{Mn}$ positions within the trinuclear molecule. While both of those are high-spin, octahedrally-coordinated

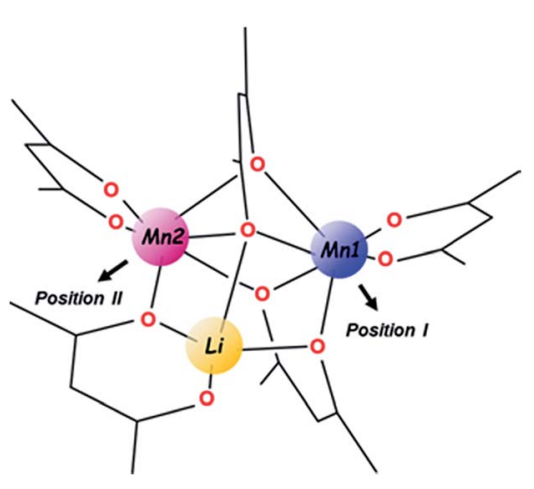

Scheme 1 
$\mathrm{Mn}^{\mathrm{II}}$ ions with one purely chelating diketonate ligand on each, the obvious visual distinction is that the Mn (2) site (position II), is bridged by oxygen from the ligand that chelates the Li center (Scheme 1). A thorough inspection of the two Mn sites in the trinuclear molecule reveals certain numerical differences (ESI, Table S8 $\dagger$ ) between them: (1) the Mn ion in position II possesses a more distorted octahedral environment than the $\mathrm{Mn}$ ion in position I ( $\sigma=14.0$ vs. 12.2); (2) the former ion also features longer averaged $\mathrm{Mn}-\mathrm{O}$ distances (2.21 vs. $2.16 \AA$ ), disregarding two chelating bonds that are essentially the same for both.

Taking into account the above structural differences between the two Mn centres, as well as inability to isolate the dicobalt analogue, $\mathrm{LiCo}_{2}(\text { thd })_{5}$, we have wondered if only one of the $\mathrm{Mn}$ sites, namely position I, could be preferentially substituted by the Co ion, which has a smaller ionic radius and tends to maintain more rigid octahedral coordination as compared to $\mathrm{Mn}$ ion. It should be noted here that the full replacement of Mn at only one specific site will bring about a "true" heterotrimetallic molecule, LiMnCo(thd $)_{5}$. On the contrary, the substitution at both positions will likely result in a mixture of heterobimetallic $\left(\mathrm{LiMn}_{2}(\text { thd })_{5}\right.$ and $\left.\mathrm{LiCo}_{2}(\text { thd })_{5}\right)$ and heterotrimetallic species as we have recently demonstrated for the $\mathrm{Li}_{2} \mathrm{CoNiL}_{6}$ system. ${ }^{54}$ In order to assess if the unique trinuclear molecule $\operatorname{LiMn}_{2}$ (thd $)_{5}$ has specific preferences for accommodating cobalt in one of its two transition metal positions, theoretical calculations of thermodynamic stability for the four possible trimetal cores (Fig. 1) were performed using the B2PLYP-D/TZVP/ZORA approach (see ESI $\dagger$ for more details). As can be seen from the results, the parent dimanganese molecule, $\operatorname{LiMn}_{2}$ (thd) ${ }_{5}$ (Fig. 1a), has the lowest stabilization energy (where $E_{\text {stabilization }}=E\left(\mathrm{LiMM}^{\prime}(\text { thd })_{5}\right)-E(\operatorname{Li}($ thd $))-E\left(\mathrm{M}(\text { thd })_{2}\right)-$

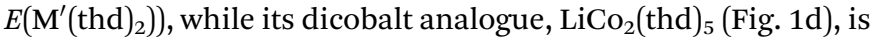
ca. $10 \mathrm{kcal} \mathrm{mol}{ }^{-1}$ higher in energy, thus being the least stable among all systems considered. Most importantly, the comparison between two isomers of the heterotrimetallic LiMnCo(thd) ${ }_{5}$ molecule (Fig. 1b and c) clearly illustrates the preference for adoption of Co at the position I and also indicates a certain feasibility (the difference of ca. $2 \mathrm{kcal} \mathrm{mol}^{-1}$ with parent $\mathrm{LiMn}_{2}$ (thd $)_{5}$ molecule) for the formation of this particular isomer.

\section{Results and discussion}

\section{Synthesis and properties}

Heterotrimetallic precursors $\operatorname{LiMn}_{2-x} \mathrm{Co}_{x}(\text { thd })_{5}(x=1$ (1a) and 0.5 (1b)) have been prepared by stoichiometric reaction between anhydrous divalent transition metal chlorides and lithium diketonate:

$$
\begin{aligned}
5 \mathrm{Li}(\text { thd })+(2-x) \mathrm{MnCl}_{2}+ & x \mathrm{CoCl}_{2} \rightarrow \\
& \mathrm{LiMn}_{2-x} \mathrm{Co}_{x}(\text { thd })_{5}+4 \mathrm{LiCl}
\end{aligned}
$$

The reaction can be run both in the solid state and in solution. For the solid state/gas phase process, the starting reagents were sealed in an evacuated ampule and placed in a gradient furnace at $110{ }^{\circ} \mathrm{C}$ (note: careful control of the temperature over time is important to avoid product decomposition), allowing crystalline products $\mathbf{1 a}$ and $\mathbf{1 b}$ to be deposited in the cooler end of the container $\left(5-10^{\circ} \mathrm{C}\right.$ lower $)$ with $\mathrm{LiCl}$ by-product remaining in the "hot" zone. While the products can be obtained in crystalline form by using this approach, it requires a long time to achieve completion, about 6 and 4 weeks for $\mathbf{1 a}$ and $\mathbf{1 b}$, respectively. Compared to the solid state method, the solution approach is faster and can be conveniently performed on a significantly larger scale. Given the decomposition temperature $\left(\mathrm{ca} .115^{\circ} \mathrm{C}\right)$ for both products, refluxing non-coordinating toluene (b.p. $111^{\circ} \mathrm{C}$ ) was used as a reaction medium. Depending on the amounts of starting reagents, it takes between 3-4 weeks for the synthesis of 1a and 2-3 weeks for $\mathbf{1 b}$ to be isolated in essentially pure form. The purple microcrystalline products can be separated from LiCl by filtration based on their different solubilities in toluene. Heterometallic precursors are highly volatile at the temperatures above $70{ }^{\circ} \mathrm{C}$. Complex 1a obtained from solution can be further purified by quantitative sublimation in evacuated ampules at as low as $90^{\circ} \mathrm{C}$.

It should be mentioned that the reaction progress in all cases can be visually controlled: the presence of pink $\operatorname{Co}(\text { thd })_{2}$ in the crystalline products clearly indicates an incomplete reaction as well as the higher than targeted $\mathrm{Mn}$ : Co ratio in the heterometallic compound. Elemental analysis of crystalline products confirmed the Li : Mn : Co metal ratios as 1:1:1 (1a) and $1: 1.5: 0.5$ (1b). Phase purity of the bulk samples obtained from the solution method has also been confirmed by the Le Bail fit

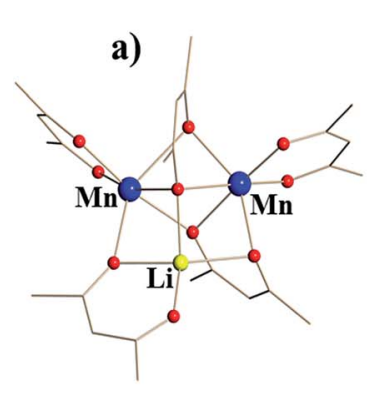

$\mathbf{- 8 2 . 7 6}$

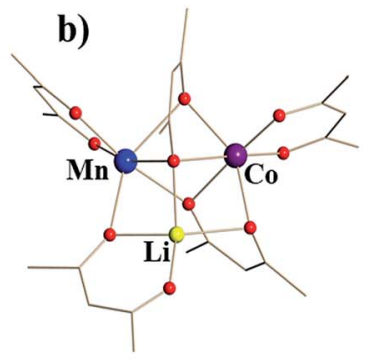

$-80.26$

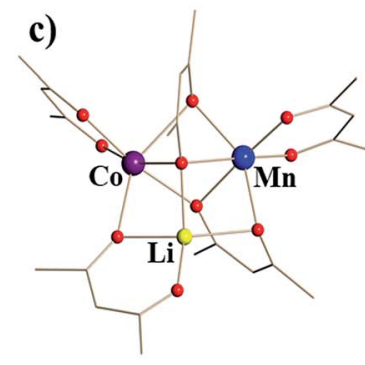

$-76.10$ d)

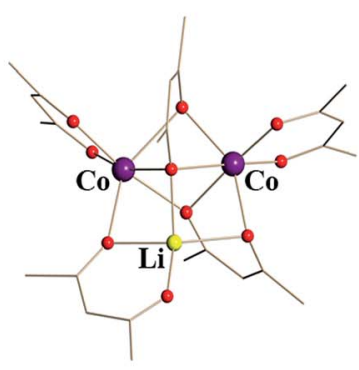

$-72.84$

Fig. 1 Calculated stabilization energies $\left(\mathrm{kcal} \mathrm{mol}^{-1}\right)$ for four possible arrangements of $\mathrm{Mn}$ and Co ions within the trinuclear LiMM' (thd) $)_{5} \mathrm{molecule}$ The tert-butyl groups and hydrogen atoms are omitted for clarity. 
of X-ray powder diffraction patterns (ESI, Fig. S1 and S2, Tables $\mathrm{S} 1$ and $\mathrm{S} 2 \dagger)$.

Apparently, at some point the substitution of Co for $\mathrm{Mn}$ proceeds according to eqn (2):

$(1-x / 2) \operatorname{LiMn}_{2}(\text { thd })_{5}+x / 2 \mathrm{Li}($ thd $)+x \mathrm{Co}(\text { thd })_{2} \rightarrow$ $\mathrm{LiMn}_{2-x} \mathrm{Co}_{x}(\text { thd })_{5}$

We have tried to run such reactions directly, only to find out that it proceeds extremely slowly, being far from completion even after 2 months at $110{ }^{\circ} \mathrm{C}$. In addition, it requires prior synthesis of $\operatorname{LiMn}_{2}$ (thd $)_{5}$ and $\mathrm{Co}$ (thd $)_{2}$ reagents.

Heterotrimetallic products $\mathbf{1 a}$ and $\mathbf{1 b}$ appear to be very similar to the parent bimetallic $\operatorname{LiMn}_{2}(\text { thd })_{5}$ diketonate in terms of volatility, solubility, and air/moisture-sensitivity. The only noticeable differences are the colour (dark-purple and purple for $\mathbf{1 a}$ and $\mathbf{1 b}$, respectively, $v$ s. bright yellow for $\mathrm{LiMn}_{2}(\text { thd })_{5}$ ) and slightly (by $5{ }^{\circ} \mathrm{C}$ ) higher decomposition temperature for the heterotrimetallic compounds. The solid, especially crystalline, products can be conveniently handled in open air in the course of characterization/decomposition studies. Complexes $\mathbf{1 a}$ and $\mathbf{1 b}$ are readily soluble in all common solvents, with the solutions being quite sensitive to open air. The NMR $\left({ }^{1} \mathrm{H}\right.$ and $\left.{ }^{7} \mathrm{Li}\right)$ spectra of both products are silent in non-/weakly-coordinating solvents, such as chloroform or acetone, indirectly confirming the retention of the heterometallic core in solution (ESI, Fig. S12-S17†). On the other hand, strongly-coordinating solvents, such as DMSO, force dissociation of the heterometallic assembly into homometallic $\mathbf{M}(\text { thd })_{2}(\mathrm{sol})_{2}$ and $\mathrm{Li}$ (thd)(sol) $)_{2}$ species, as evidenced by the appearance of diamagnetic component signals in the NMR spectra (ESI, Fig. S18 and S19†).

It should be stressed here again that all our attempts to prepare heterobimetallic $\mathrm{LiCo}_{2}$ (thd) $)_{5}$ analogue (or even detect it as a minor product) have failed regardless of synthetic methods, experimental conditions, and starting reagents utilized. Analysis of the isolated products by X-ray single crystal/powder diffraction and mass spectrometry techniques did not provide any evidence for the existence of the dicobalt compound; the reaction mixtures were always found to contain only $\mathrm{Co}$ (thd $)_{2}$ and $\mathrm{Li}$ (thd) homometallic diketonates.

\section{Crystal structure}

Single crystal X-ray investigations of heterotrimetallic precursors $1 \mathbf{a}$ and $\mathbf{1 b}$ confirm that they are isomorphous to $\mathrm{LiMn}_{2}(-$ thd $)_{5}$ and crystallize in the centrosymmetric triclinic space group with very close unit cell parameters (ESI, Table S9†). Similar to the parent compound, the crystal structures of $\mathbf{1 a}$ and 1b are rather complex, containing two crystallographically independent molecules in the unit cells. While one of those molecules is perfectly ordered (Fig. 2), the other one is severely disordered. As in the parent structure, this disorder can be fully modelled to reveal a superposition of two enantiomers: $S$-Li, $\Delta$ Co, $\Lambda$-Mn and $R$-Li, $\Lambda$-Co, $\Delta$-Mn (ESI, Fig. $\mathrm{S} 4 \dagger$ ), both refined with the site occupancy factor of 0.5 for every atom.

As may be expected, the refinement of structure 1a with Co placed either in position I or II, as well as with mixed occupancy

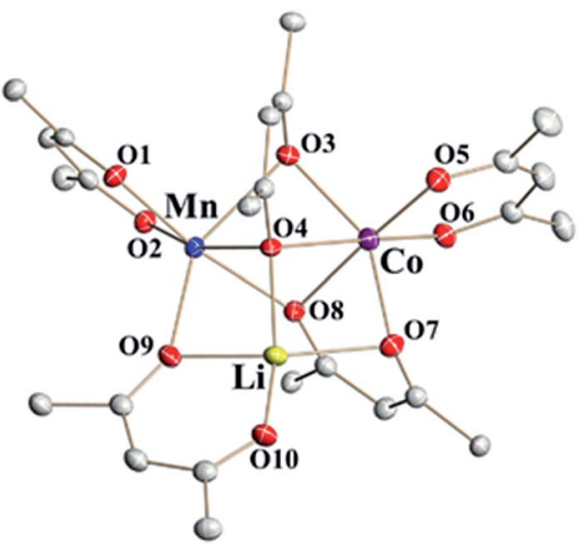

Fig. 2 Heterotrimetallic molecule that represents the ordered unit in the structure of $\mathrm{LiMnCo}(\mathrm{thd})_{5}$ (1a). Hydrogen atoms and tert-butyl groups of thd ligands are omitted for clarity. Full view of trimetallic molecules in the structures $1 \mathrm{a}$ and $1 \mathrm{~b}$ can be found in ESI, Fig. S3 and S6.†

Co : $\mathrm{Mn}=0.5: 0.5$ for both positions, did not result in any significant alterations of $R$-values, standard deviations, or atomic displacement parameters for the metal sites involved (ESI, Table S6†).

However, a careful analysis of $\mathrm{M}-\mathrm{O}$ distances (possible for ordered units only) in structures $\mathbf{1 a}$ and $\mathbf{1 b}$ and their comparison to the corresponding bonds in the parent structure of $\mathrm{LiMn}_{2}(\text { thd })_{5}$ revealed an incontestable trend (Table 1). While the distances for the metal in position II remain almost the same as in the all-Mn structure, those for the metal in position I appeared to be significantly shorter. This observation clearly indicates that only position $\mathbf{I}$ in the structures of $\mathbf{1 a}$ and $\mathbf{1 b}$ contains Co (fully or partially), while position II remains occupied solely by $\mathrm{Mn}$ in accord with predictions made by theoretical calculations (vide supra). The differences in $\mathrm{M}-\mathrm{O}$ distances in structure $\mathbf{1 b}$ follow the above trend, although not as distinctly as those in structure 1a, which corresponds well to the lower content of Co in the former compound.

The above observations imply that the structure of LiMnCo(thd $)_{5}$ (1a) consists of "true" heterotrimetallic molecules as shown in Fig. 2, while the structure of $\mathrm{LiMn}_{1.5} \mathrm{Co}_{0.5}(-$ thd $)_{5}$ (1b) should contain a statistical mixture of heterotrimetallic LiMnCo(thd $)_{5}$ and heterobimetallic $\operatorname{LiMn}_{2}(-$ thd $)_{5}$ units (ESI, Fig. S6 $\dagger$ ). However, since this conclusion can be drawn upon consideration of the ordered trinuclear units only, other characterization methods should be employed for analysis of the "whole" structure.

\section{Resonant diffraction investigation}

Due to the close atomic numbers of $\mathrm{Mn}$ and Co, as well as similar radii of their divalent ions, single crystal X-ray diffraction data cannot be used for unambiguous assignment of $3 \mathrm{~d}$ transition metal positions, let alone the precise refinement of Mn : Co ratios for the mutually occupied positions in both ordered and disordered units of structures $\mathbf{1 a}$ and $\mathbf{1 b}$. In order to resolve this problem, X-ray resonant diffraction investigation, 
Table 1 Comparison of the metal-oxygen bond lengths $(\Delta, \AA$, negative values stand for "shorter") in ordered trinuclear units of heterotrimetallic compounds $1 \mathrm{a}$ and $1 \mathrm{~b}$ with corresponding distances in the parent heterobimetallic molecule $\mathrm{LiMn}_{2}(\mathrm{thd})_{5}$. The full list of the bond distances and angles can be found in ESI, Tables S5 and S7. Oxygen atom labels match those in Fig. $2^{a}$

\begin{tabular}{|c|c|c|c|c|c|}
\hline & & & $\begin{array}{l}\mathrm{LiMnCo}(\text { thd })_{5}(\mathbf{1 a}) \\
\Delta(\mathrm{M}-\mathrm{O}), \AA\end{array}$ & $\begin{array}{l}\mathrm{LiMn}_{1.5} \mathrm{Co}_{0.5}(\mathrm{thd})_{5}(\mathbf{1 b}) \\
\Delta(\mathrm{M}-\mathrm{O}), \AA\end{array}$ & $\begin{array}{l}\operatorname{LiMn}_{2}(\text { thd })_{5}{ }^{51} \\
\mathrm{M}-\mathrm{O}, \AA\end{array}$ \\
\hline \multirow{6}{*}{ Position I } & \multirow{2}{*}{$\mathrm{M}-\mathrm{O}_{\mathrm{c}}$} & O5 & -0.052 & -0.040 & $2.045(3)$ \\
\hline & & O6 & -0.051 & -0.037 & $2.074(2)$ \\
\hline & \multirow{4}{*}{$\mathrm{M}-\mathrm{O}_{\mathrm{b}}$} & $\mathrm{O} 3$ & -0.047 & -0.037 & $2.189(2)$ \\
\hline & & $\mathrm{O} 4$ & -0.045 & -0.037 & $2.304(2)$ \\
\hline & & $\mathrm{O} 7$ & -0.066 & -0.048 & $2.157(3)$ \\
\hline & & O8 & -0.039 & -0.032 & $2.187(2)$ \\
\hline \multirow{6}{*}{ Position II } & \multirow{3}{*}{$\mathrm{M}-\mathrm{O}_{\mathrm{c}}$} & O1 & -0.001 & -0.003 & $2.079(2)$ \\
\hline & & $\mathrm{O} 2$ & -0.001 & -0.003 & $2.059(2)$ \\
\hline & & $\mathrm{O} 3$ & -0.013 & -0.011 & $2.335(2)$ \\
\hline & \multirow{3}{*}{$\mathrm{M}-\mathrm{O}_{\mathrm{b}}$} & $\mathrm{O} 4$ & 0.013 & 0.002 & $2.304(2)$ \\
\hline & & O8 & -0.012 & -0.011 & $2.210(2)$ \\
\hline & & O9 & 0.003 & 0.003 & $2.162(3)$ \\
\hline
\end{tabular}

which is based on application of wavelengths near-edge of anomalous X-ray scatterers, was carried out to identify the presence of $\mathrm{Mn} / \mathrm{Co}$ at particular metal sites and to quantitatively determine their individual occupancy factors at the mixedmetal sites in the structure of $\operatorname{LiMn}_{1.5} \mathrm{Co}_{0.5}(\text { thd })_{5}(\mathbf{1 b})$. Manganese and cobalt exhibit significant differences in the anomalous dispersion factors at their X-ray absorption edges, while the dispersion factors of other elements remain constant. Thus, the employment of the specific wavelength at $\mathrm{Mn} / \mathrm{Co}$ K-edges allows for a site-specific elemental analysis as well as for quantitative estimation of occupancies and associated relative errors. A total of seven datasets at seven different wavelengths (three at or near Mn K-edge, three at or near Co K-edge, and one away from both absorption edges) were collected during the resonant diffraction experiment (ESI, Fig. S7 and S8†).

For the ordered crystallographic unit in the structure of $\mathbf{1 b}$, the metal site occupation pattern can be effectively visualized by inspecting the difference Fourier electron density maps that display deep holes for the respective crystallographic metal positions (Fig. 3). It has been unambiguously found that in the ordered crystallographically independent molecule, both of the transition metal sites contain $\mathrm{Mn}$, while only one of those (position I) exhibits Co K-edge absorption, thus indicating the presence of Co. In order to minimize the solid-state effects neglected for calculations of dispersion factors, the data sets collected on the lower-energy side of the respective absorption edges and at $30 \mathrm{keV}$ were used for the quantification of metal occupancies in the ordered unit of structure $\mathbf{1 b}$. It was confirmed that Mn fully occupies position II (s.o.f. $=0.995(1)$ ), while position I contains both $\mathrm{Mn}$ and Co in a nearly equiatomic ratio of $0.476(3) / 0.524(3)$. Thus, the structural analysis revealed that this unit (c) is built upon the intergrowth of two different molecules, $\operatorname{LiMn}_{2}(\text { thd })_{5}(\mathbf{a})$ and $\operatorname{LiMnCo}(\text { thd })_{5}(\mathbf{b})$, in a $1: 1$ ratio (Fig. 4) to maintain the composition $\operatorname{LiMn}_{1.5} \mathrm{Co}_{0.5}(\mathrm{thd})_{5}$.

For the disordered unit, the modelling appears significantly more challenging. Based on our refinement of the parent

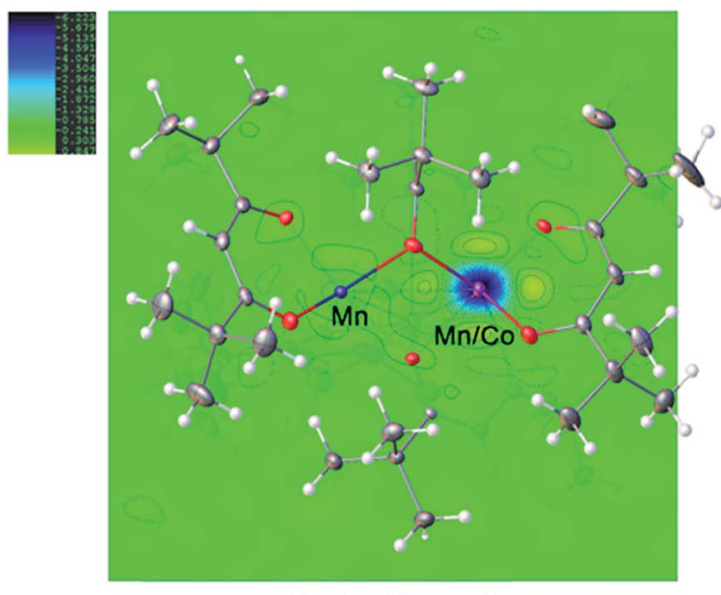

Co K-edge $(7709 \mathrm{eV})$
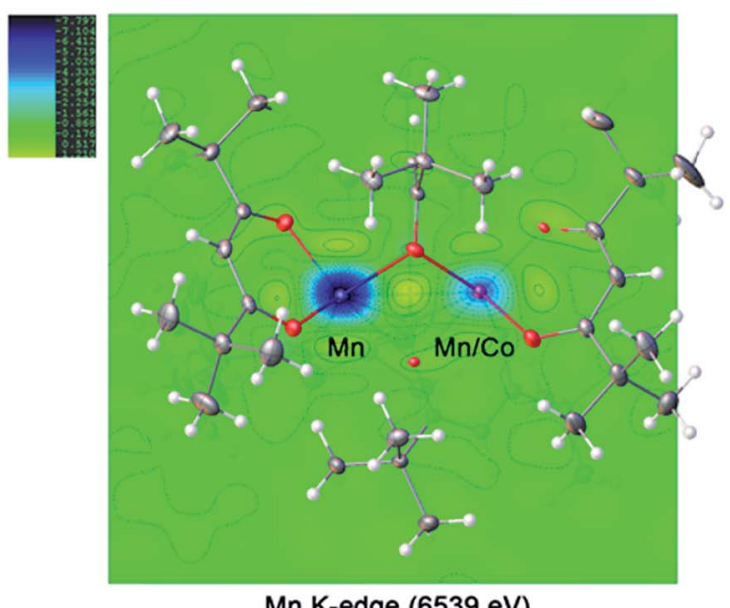

Fig. 3 Difference Fourier electron density maps at absorption K-edges of $\mathrm{Co}$ and $\mathrm{Mn}$ for the ordered trinuclear units in the structure of $\mathrm{LiMn}_{1.5} \mathrm{CO}_{0.5}(\text { thd })_{5}(\mathrm{bb})$. 


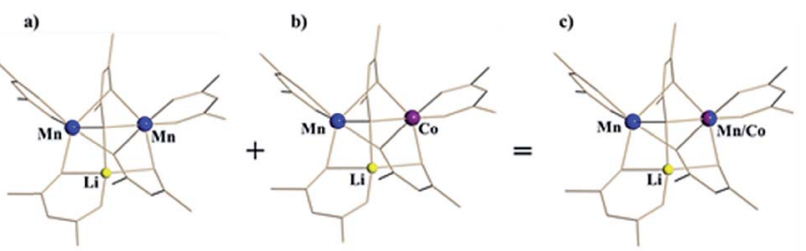

Fig. 4 Ordered unit (c) in the crystal structure of $\mathrm{LiMn}_{1.5} \mathrm{CO}_{0.5}(\text { thd })_{5}$ (1b) as a superposition of heterobimetallic $\operatorname{LiMn}_{2}(\text { thd })_{5}$ (a) and heterotrimetallic LiMnCo(thd) $)_{5}$ (b) molecules in $1: 1$ ratio.

structure $\operatorname{LiMn}_{2}(\text { thd })_{5},{ }^{51}$ the reasonable model for a disordered unit (d) can be achieved by refining it as a superposition of molecule $\mathbf{c}(S, \Delta, \Lambda)$ and its enantiomer o $(R, \Lambda, \Delta)$ taken in $1: 1$ ratio (Fig. 5). Refinement of occupancy factors for metal positions in two individual molecules that comprise the disordered unit yields $0.500(1)$ and $0.496(1)$ for $\mathrm{Mn}$ and $0.241(3) / 0.259(3)$ for mixed $\mathrm{Mn} / \mathrm{Co}$ sites, respectively (occupancies for mixed $\mathrm{Mn} / \mathrm{Co}$ sites of two disordered molecules were constrained to be equal). Thus, the total composition of the disordered unit is essentially the same as that of the ordered one. Overall, these results are in excellent agreement with the formulation of $\mathbf{1 b}$ as $\mathrm{LiMn}_{1.5} \mathrm{Co}_{0.5}$ (thd $)_{5}$, as determined by elemental analysis, unambiguously confirming the substitution of Co for $\mathrm{Mn}$ in position I only.

\section{Direct analysis in real time (DART) mass spectrometry investigation}

Presumably, mass spectrometry is an ideal method to provide accessible, fast, and unambiguous assessment of the presence of heterotrimetallic molecules $v s$. the mixture of heterobimetallic counterparts or all of the above. It should work well when the two transition metals are well-separated in terms of their atomic masses and isotope distribution patterns, unlike the recently reported case of the $\mathrm{Li}-\mathrm{Co}-\mathrm{Ni}$ system. ${ }^{54}$ However, for successful application of mass spectrometry it is important that heterometallic molecules exhibit a certain degree of structural integrity in maintaining heterometallic ions at experimental conditions and do not undergo excessive fragmentation/recombination processes in the mass spectrometer. To this end, the Direct Analysis in Real Time (DART) mass spectrometry has already demonstrated ${ }^{3,49,54,55}$ great promise in retention of heterometallic assemblies due to its soft ionization characteristics, allowing for the effective analysis of the "gas-phase structure", as well as for identifying the chemical

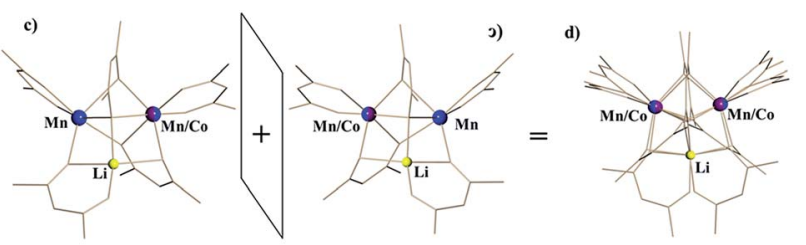

Fig. 5 Disordered unit (d) in the crystal structure of $\mathrm{LiMn}_{1.5} \mathrm{Co}_{0.5}(\text { thd })_{5}$ (1b) as a superposition of two enantiomers ( $S, \Delta, \Lambda-C$ and $R, \Lambda, \Delta-$ - $)$. compositions based on the detected ionic species and their isotope distribution patterns.

In the positive mode mass spectrum of the solid precursor LiMnCo(thd $)_{5}$ (1a), its heterotrimetallic character is unambiguously revealed by the presence of two parent ions, $[\mathrm{M}+\mathrm{H}]^{+}(\mathrm{M}$ $=\mathrm{LiMnCoL}_{5} ; \mathrm{L}=$ thd; meas/calcd $\left.=1037.5812 / 1037.5877\right)$ and $[\mathrm{M}-\mathrm{L}]^{+}$(meas/calcd $\left.=853.4409 / 853.4414\right)$, along with their characteristic isotope distribution patterns (Fig. 6). Importantly, there are no visible peaks that can be assigned to the corresponding heterobimetallic counterparts $\mathrm{LiMn}_{2} \mathrm{~L}_{5}$ and $\mathrm{LiCo}_{2} \mathrm{~L}_{5}$ (ESI, Fig. S20, S23, and Table S10 $\dagger$ ). These observations provide a conclusive evidence that the title complex 1a consists solely of heterotrimetallic trinuclear molecules LiMnCo(thd) $)_{5}$.

According to the results of resonant diffraction analysis, precursor $\mathrm{LiMn}_{1.5} \mathrm{Co}_{0.5}(\text { thd })_{5}$ (1b) contains heterotrimetallic LiMnCo(thd $)_{5}$ and heterobimetallic $\mathrm{LiMn}_{2}$ (thd $)_{5}$ molecules cocrystallized in $1: 1$ ratio. Thus, one should observe the peaks in mass spectrum that represent both corresponding ions. While the heterotrimetallic peak $[\mathrm{M}-\mathrm{L}]^{+}\left(\mathrm{M}=\mathrm{LiMnCoL}_{5} ; \mathrm{L}=\right.$ thd; meas/calcd $=853.4409 / 853.4413$ ) was clearly identified (Fig. 7), the corresponding heterobimetallic $\left[\mathrm{LiMn}_{2} \mathrm{~L}_{4}\right]^{+}$pattern was found to be severely overlapped (ESI, Table S13†) with one of the major fragmentation products $\left[\mathrm{MnCoL}_{4}+\mathrm{H}\right]^{+}$. The latter ion was also encountered in the mass spectrum of 1a, where its experimental isotope distribution pattern fits well with the simulated one (ESI, Table S12 $\dagger$ ), indicating the absence of the $\left[\mathrm{LiMn}_{2} \mathrm{~L}_{4}\right]^{+}$ion. On the contrary, the experimental isotope distribution pattern of $\left[\mathrm{MnCoL}_{4}+\mathrm{H}\right]^{+}$ion in the spectrum of $\mathbf{1 b}$ does not match the simulated one, especially considering the intensities of the peaks at $m / z=849,850$, and 851 , which are significantly higher than calculated values. After a careful analysis, the individual intensities were successfully extracted as $19 \%$ and $81 \%$ for the $\left[\mathrm{LiMn}_{2} \mathrm{~L}_{4}\right]^{+}$and $\left[\mathrm{MnCoL}_{4}+\mathrm{H}\right]^{+}$ions, respectively, and the satisfactory fit between calculated and experimental patterns was obtained (ESI, Fig. S22 and Table

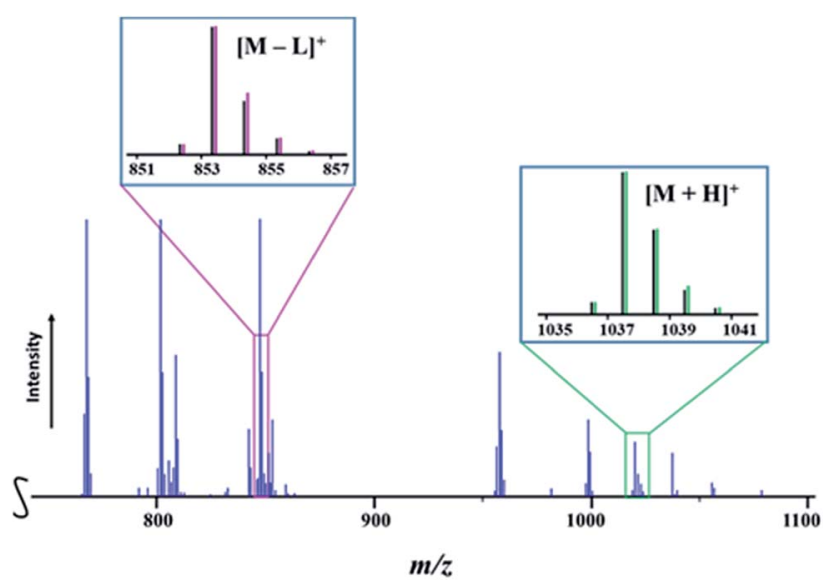

Fig. 6 Fragment of the positive ion DART mass spectrum of solid $\mathrm{LiMnCo}$ (thd $)_{5}(1 \mathrm{a})$. The isotope distribution patterns for the $[\mathrm{M}+\mathrm{H}]^{+}$ and $[\mathrm{M}-\mathrm{L}]^{+}\left(\mathrm{M}=\mathrm{LiMnCo}(\mathrm{thd})_{5}, \mathrm{~L}=\right.$ thd) ions are shown as insets. Black and pink/green lines are experimental and simulated patterns, respectively. The full spectrum and peak assignments can be found in ESI, Fig. S20 and Tables S10-S12.† 


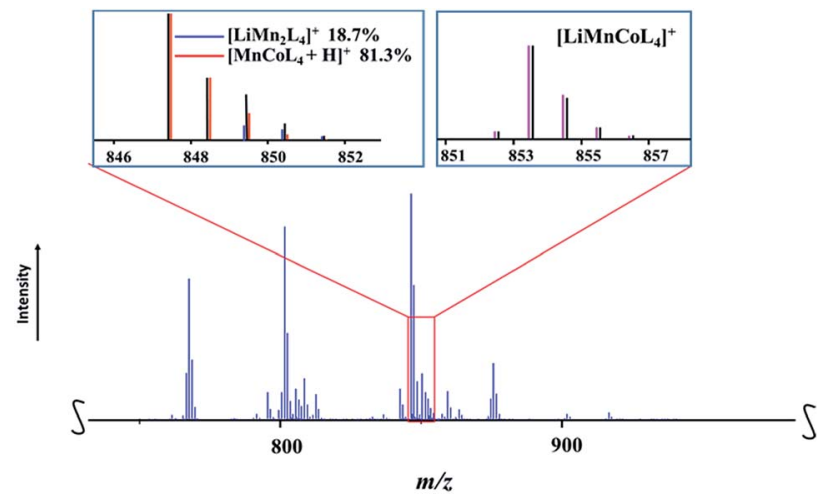

Fig. 7 Fragment of the positive ion DART mass spectrum of solid $\mathrm{LiMn}_{1.5} \mathrm{CO}_{0.5}(\mathrm{thd})_{5}$ (1b). The isotope distribution pattern for the $\left[\mathrm{LiMnCoL}_{4}\right]^{+}(\mathrm{L}=$ thd $)$ ion and overlapped pattern for $\left[\mathrm{LiMn}_{2} \mathrm{~L}_{4}\right]^{+}$and $\left[\mathrm{MnCoL}_{4}+\mathrm{H}\right]^{+}$ions are shown as insets. Black and red/blue/pink lines are experimental and simulated patterns, respectively. The full spectrum and peak assignments can be found in ESI, Fig. S21 and S22, Tables S13-S16.广

S16†). Thus the DART mass spectrometry investigation also confirms that heterometallic precursor $\mathbf{1 b}$ contains both LiMnCo(thd $)_{5}$ and $\operatorname{LiMn}_{2}$ (thd $)_{5}$ molecules. As in the mass spectrum of 1a, no evidence for the presence of $\mathrm{LiCo}_{2}(\text { thd })_{5}$ molecule was found (ESI, Fig. S23†).

\section{Magnetic measurement of heterometallic complexes}

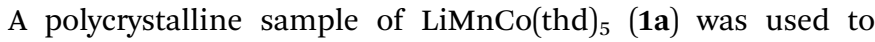
investigate its magnetic behavior in comparison to that of parent $\mathrm{LiMn}_{2}$ (thd) $)_{5}$. Both complexes exhibit a gradual decrease in the product of magnetic susceptibility $(\chi)$ by temperature $(T)$ upon cooling (Fig. 8). Fitting the linear part of inverse susceptibility for $\mathrm{LiMn}_{2}(\text { thd })_{5}$ to the Curie-Weiss law, $1 / \chi=(T-\theta) / C$, resulted in the Curie constant $(C)$ equal to $9.46(4) \mathrm{emu} \mathrm{K} \mathrm{mol}^{-1}$ and the Weiss constant $(\theta)$ equal to $-36(1) \mathrm{K}\left(R^{2}=9996\right)$. While the value of $C$ is slightly higher than $8.75 \mathrm{emu} \mathrm{K} \mathrm{mol}^{-1}$ expected for two non-interacting high-spin $(S=5 / 2) \mathrm{Mn}^{2+}$ ions, the negative Weiss constant and the gradual decrease in the $\chi T$ product indicate antiferromagnetic exchange coupling between the $\mathrm{Mn}^{2+}$ centres. The temperature dependence of $\chi T$ was modelled with an isotropic Heisenberg-Dirac-Van Vleck Hamiltonian, $\hat{\mathbf{H}}=-2 J \hat{\mathbf{S}}_{1} \hat{\mathbf{S}}_{2}$, and the fit to the experimental data (Fig. 8a) yielded the exchange coupling constant $J=$ $-2.53(4) \mathrm{cm}^{-1}$ and the Lande factor $g=2.022(2)\left(R^{2}=9970\right)$. The $g$-factor seems to be somewhat high for the magnetically isotropic $\mathrm{d}^{5} \mathrm{Mn}^{2+}$ ion, but this might be due to the slight error in the mass measurement of $\operatorname{LiMn}_{2}$ (thd $)_{5}$ crystals that were contained in a sealed NMR tube to avoid oxidation of the sample.

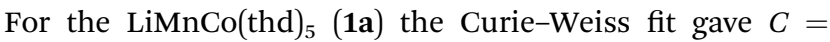
7.34(2) emu $\mathrm{K} \mathrm{mol}^{-1}$ and $\theta=-25.6(5) \mathrm{K}$. The Curie constant exceeds the spin-only value of $6.25 \mathrm{emu} \mathrm{K} \mathrm{mol}^{-1}$ expected for the non-interacting $\mathrm{Mn}^{2+}(S=5 / 2)$ and $\mathrm{Co}^{2+}(S=3 / 2)$ ions, which appears reasonable, given the well-known tendency for the $\mathrm{Co}^{2+}$ ion to exhibit the orbital contribution to its magnetic moment and substantial spin-orbit coupling. While the negative Weiss constant and the decrease in the $\chi T$ product with temperature suggest antiferromagnetic exchange coupling within the dimers, the situation is complicated by the fact that the Curie-Weiss fit also absorbs the spin-orbit coupling and zero-field splitting effects, which will effectively make the $\theta$ value appear more negative.

Related to the preceding discussion, the question about chemical composition of trinuclear units in LiMnCo(thd $)_{5}$ (1a) is critical to understanding the magnetic behaviour of this complex. In this vein, an important observation can be made on the low-temperature behaviour of the $\chi T$ product. For the parent molecule $\mathrm{LiMn}_{2}$ (thd) $)_{5}$, the $\chi T$ value tends to zero (Fig. 8a), as can be expected for the $S_{\text {total }}=0$ ground state resulting from the mutual cancellation of two antiferromagnetically coupled $S=5$ / 2 centers. A similar behaviour would be expected for LiMnCo(thd $)_{5}$ (1a) if its crystal structure contained only heterobimetallic $\mathrm{LiMn}_{2}$ (thd $)_{5}$ and $\mathrm{LiCo}_{2}$ (thd $)_{5}$ molecules. This is not what is observed experimentally: the $\chi T$ product of LiMnCo(thd $)_{5}$ (1a) decreases to a finite value of $\sim 0.5 \mathrm{emu} \mathrm{K}$ $\mathrm{mol}^{-1}$ at $1.8 \mathrm{~K}$ (Fig. 8b). The consequence can be seen in the temperature dependence of $1 / \chi$, which for $\operatorname{LiMn}_{2}(\text { thd })_{5}$ diverges at lower temperature, due to the stabilization of the $S_{\text {total }}=$ 0 ground state (Fig. 8a, inset), while for LiMnCo(thd) $)_{5}$ (1a) the $1 /$ $\chi$ curve tends to a constant value (Fig. $8 \mathrm{~b}$, inset).

Additional support for the heterotrimetallic nature of LiMnCo(thd $)_{5}$ (1a) was obtained by field-dependent magnetization measurements performed at $1.8 \mathrm{~K}$. In the case of $\operatorname{LiMn}_{2}(\text { thd })_{5}$, the magnetization exhibits a slow linear growth, as expected for the antiferromagnetically coupled homometallic (Mn) dimer, but a steeper growth can be seen at fields above $4 \mathrm{~T}$ (Fig. 8c). Taking into account the rather small exchange constant of $-2.53(4) \mathrm{cm}^{-1}$, the observed behavior is explained by the field-induced population of the Zeeman-split excited states with non-zero $S_{\text {total }}$ values. If the sample of LiMnCo(thd) (1a) contained only heterobimetallic species, one would assume that its field-dependent magnetization should be reflected by the sum of magnetizations of the individual $\operatorname{LiMn}_{2}(\text { thd })_{5}$ and $\mathrm{LiCo}_{2}(\text { thd })_{5}$ molecules, since the dipolar intermolecular coupling should be negligible due to the bulkiness of the thd ligands. Although the heterobimetallic $\mathrm{LiCo}_{2}(\text { thd })_{5}$ complex is not available to verify this hypothesis, the field-dependent magnetization curve for LiMnCo(thd) $)_{5}$ (1a) does not reveal a steep increase above $4 \mathrm{~T}$ (Fig. 8d), as it was observed for $\mathrm{LiMn}_{2}(\text { thd })_{5}$. The magnetization measured for $\mathbf{1 a}$ exhibits a nearly linear increase from 0 to $7 \mathrm{~T}$, and the higher magnetization value observed at $7 \mathrm{~T}$, as compared to the value found for $\mathrm{LiMn}_{2}$ (thd $)_{5}$, is consistent with the heterotrimetallic nature of LiMnCo(thd $)_{5}$ (1a) and non-zero spin ground state in such molecule. To examine the field-dependent magnetization curves of these two samples more carefully, we show their derivatives as insets in Fig. $8 \mathrm{c}$ and $\mathrm{d}$, respectively. The $\mathrm{d} M / \mathrm{d} H$ plot for $\mathrm{LiMnCo}$ (thd $)_{5}$ (1a) reveals a feature at $\sim 5 \mathrm{~T}$, similar to that seen in the $\mathrm{d} M / \mathrm{d} H$ plot for $\mathrm{LiMn}_{2}(\text { thd })_{5}$ at $\sim 4.5 \mathrm{~T}$. Thus, a weak inflection is still present in the $M v s$. $H$ plot of 1a, suggesting that the sample might contain a small amount of heterobimetallic $\mathrm{LiMn}_{2}$ (thd $)_{5}$ molecules. Such effect might be due to the $\mathrm{Mn}$ : Co ratio in the sample slightly exceeding the parity. Overall, however, the observed low-temperature magnetic 

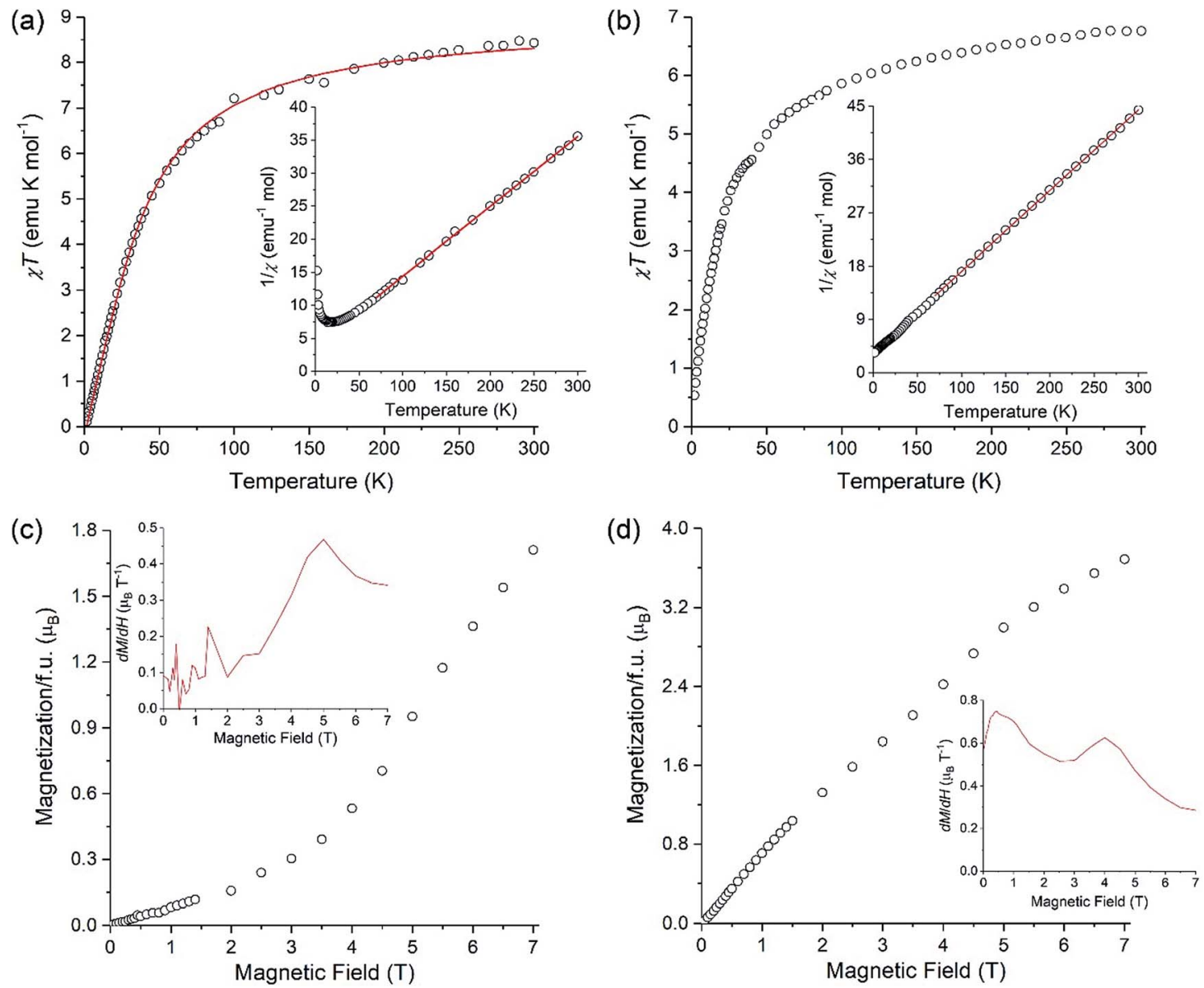

Fig. 8 Temperature dependencies of $\chi T$ measured at applied magnetic field of $0.1 \mathrm{~T}$ and field dependencies of magnetization measured at $1.8 \mathrm{~K}$ for LiMn ${ }_{2}(\text { thd })_{5}(a \text { and C) and LiMnCo(thd })_{5}$ (b and d). The solid red line in (a) shows the theoretical fit. The insets in (a) and (b) show the CurieWeiss fit (solid red lines) for the temperature dependences of $1 / \chi$, while the insets in (c) and (d) display the first derivative of magnetization over applied magnetic field.

behaviour of LiMnCo(thd $)_{5}(\mathbf{1 a})$ is consistent with the presence of heterotrimetallic molecules in its crystal structure.

\section{Thermal decomposition of heterometallic precursors}

Investigation of thermal behaviour of heterometallic precursors LiMnCo(thd $)_{5}$ (1a) and $\mathrm{LiMn}_{1.5} \mathrm{Co}_{0.5}(\text { thd })_{5}(\mathbf{1 b})$ revealed that both compounds exhibit clean, low-temperature decomposition patterns, yielding phase-pure $\mathrm{LiMnCoO}_{4}$ and $\mathrm{LiMn}_{1.5} \mathrm{Co}_{0.5} \mathrm{O}_{4}$ spinel oxides. The degradation of precursors starts around $115{ }^{\circ} \mathrm{C}$, while fast weight loss occurs in a single step around 148-150 ${ }^{\circ} \mathrm{C}$ and ends around $275-280{ }^{\circ} \mathrm{C}$ (ESI, Fig. S24†). The total weight loss is $83.13 \%$ and $82.24 \%$ that corresponds well to theoretical values of $82.2 \%$ and $82.1 \%$ for precursors $1 \mathbf{a}$ and $\mathbf{1 b}$, respectively. The traces of target products become visible in the $\mathrm{X}$-ray powder patterns at around $350{ }^{\circ} \mathrm{C}$ along with a number of unidentified peaks, suggesting the incomplete decomposition process. The phase-pure oxides can be obtained at temperatures as low as $400{ }^{\circ} \mathrm{C}$ (Fig. 9). The crystallinity of the decomposition residues can be greatly improved upon elevating the annealing temperature to $550{ }^{\circ} \mathrm{C}$ (ESI, Fig. S25-S30†), and the unit cell parameters of thermolysis products (Table 2), calculated from the Le Bail fit, correspond well to the literature data. On the other hand, an appearance of red crystalline $\mathrm{Li}_{2} \mathrm{MnO}_{3}$ can be visually observed above $550{ }^{\circ} \mathrm{C}$ and further confirmed by X-ray powder diffraction analysis, indicating the subsequent decomposition of spinel phases.

The crystal structure and compositional homogeneity of the spinels obtained at $550{ }^{\circ} \mathrm{C}$ have been investigated with electron diffraction (ED), transmission electron microscopy (TEM), high

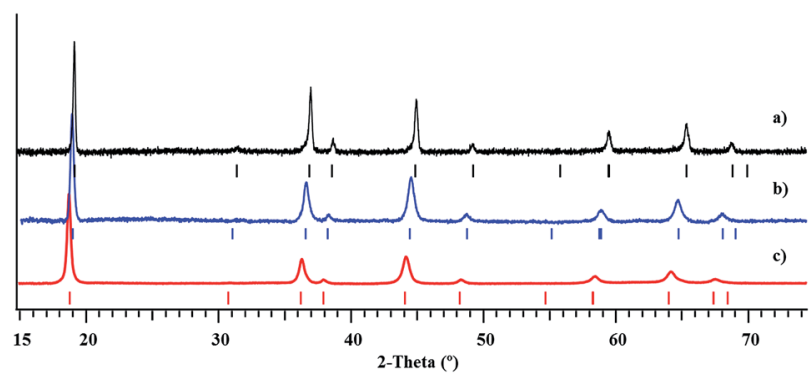

Fig. 9 X-ray powder diffraction patterns of $\mathrm{LiMnCoO}_{4}$ (a), $\mathrm{LiMn}_{1.5^{-}}$ $\mathrm{CO}_{0.5} \mathrm{O}_{4}$ (b), and $\mathrm{LiMn}_{2} \mathrm{O}_{4}$ (c) ${ }^{51}$ obtained from the thermal decomposition of the corresponding heterometallic precursors at $450{ }^{\circ} \mathrm{C}$. 
Table 2 Comparison of the unit cell parameters (Sp. Gr. Fd $\overline{3} m$ ) of spinel oxides obtained by thermal decomposition of heterometallic precursors $1 \mathrm{a}$ and $1 \mathrm{~b}$ with literature data

\begin{tabular}{lll}
\hline Compound & Temperature & $a(\AA)$ \\
\hline $\mathrm{LiMnCoO}_{4}$ & $400{ }^{\circ} \mathrm{C}$ & $8.0572(2)$ \\
& $550^{\circ} \mathrm{C}$ & $8.0601(2)$ \\
& Reported $^{56}$ & $8.05679(3)$ \\
$\mathrm{LiMn}_{1.5} \mathrm{Co}_{0.5} \mathrm{O}_{4}$ & $400{ }^{\circ} \mathrm{C}$ & $8.1362(2)$ \\
& $550{ }^{\circ} \mathrm{C}$ & $8.1358(1)$ \\
$\mathrm{LiMn}_{2} \mathrm{O}_{4}$ & Reported $^{23}$ & $8.138(2)$ \\
& Reported $^{57}$ & $8.2211(4)$
\end{tabular}

angle annular dark field scanning TEM (HAADF-STEM), and energy dispersive X-ray (EDX) analysis using an aberrationcorrected Titan G3 electron microscope operated at $200 \mathrm{kV}$ and equipped with Super-X EDX system. Electron diffraction patterns of $\mathrm{LiMnCoO}_{4}$ and $\mathrm{LiMn}_{1.5} \mathrm{Co}_{0.5} \mathrm{O}_{4}$ (Fig. 10 and $\mathrm{S} 31$ of ESI, $\dagger$ respectively) revealed an $F$-centred cubic unit cell with $a \approx$ $8.1 \AA$, characteristic of the spinel type structure. The $h k 0, h+k=$ $4 n, h, k$ - even, reflection condition visible in the [001] ED pattern confirms the space group $F d \overline{3} m$.

The TEM images in Fig. 11a and S30a † show that the spinels crystallize in a form of truncated octahedral crystals with the size ranging between $50-200 \mathrm{~nm}$ for $\mathrm{LiMnCoO}_{4}$ and 100$300 \mathrm{~nm}$ for $\mathrm{LiMn}_{1.5} \mathrm{Co}_{0.5} \mathrm{O}_{4}$. High-resolution [011] HAADF-STEM images of $\mathrm{LiMnCoO}_{4}$ and $\mathrm{LiMn}_{1.5} \mathrm{Co}_{0.5} \mathrm{O}_{4}$ (Fig. 11b and $\mathrm{S} 32 \mathrm{~b}, \dagger$ respectively) reveal well-ordered spinel structures for both decomposition residues. The bright and faint dots in these images stand for the projections of the columns of the $16 \mathrm{~d}$ positions occupied by the transition metal cations. The difference in brightness occurs because of different projected density of atoms being viewed along [011] direction. The Li and $\mathrm{O}$ atoms at the $8 \mathrm{a}$ and $32 \mathrm{e}$ positions, respectively, are not visible because of their low atomic numbers.

Importantly, the compositional EDX maps show highly homogeneous distribution of $\mathrm{Mn}$ and $\mathrm{Co}$ in both $\mathrm{LiMnCoO}_{4}$ and $\mathrm{LiMn}_{1.5} \mathrm{Co}_{0.5} \mathrm{O}_{4}$ oxides (ESI, Fig. S33 and S34†). Quantitative EDX analysis revealed the $\mathrm{Mn}$ : Co atomic ratio to be close to the nominal chemical composition of $0.92(2): 1.08(2)$ for $\mathrm{LiMnCoO}_{4}$. For $\mathrm{LiMn}_{1.5} \mathrm{Co}_{0.5} \mathrm{O}_{4}$ the $\mathrm{Mn}$ : Co ratio of $1.37(3): 0.63(3)$ reflects somewhat lower manganese content as compared to the corresponding heterometallic precursor. The latter can be explained by the fact that $\operatorname{LiMn}_{1.5} \mathrm{Co}_{0.5}(\text { thd })_{5}(\mathbf{1 b})$ precursor used for the preparation of oxide was shown to contain both heterotrimetallic LiMnCo(thd $)_{5}$ and

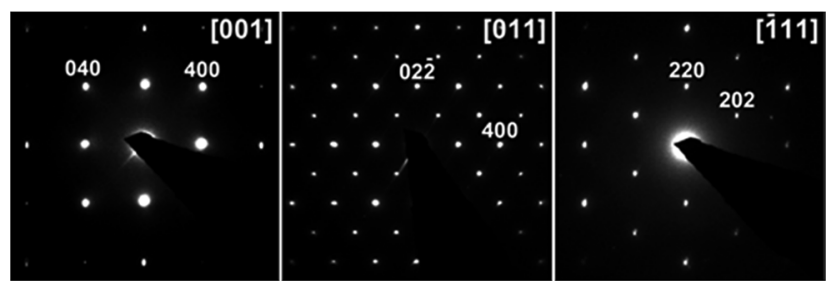

Fig. 10 Electron diffraction patterns of $\mathrm{LiMnCoO}_{4}$ obtained by thermal decomposition of heterometallic precursor $1 \mathrm{a}$ at $550{ }^{\circ} \mathrm{C}$.

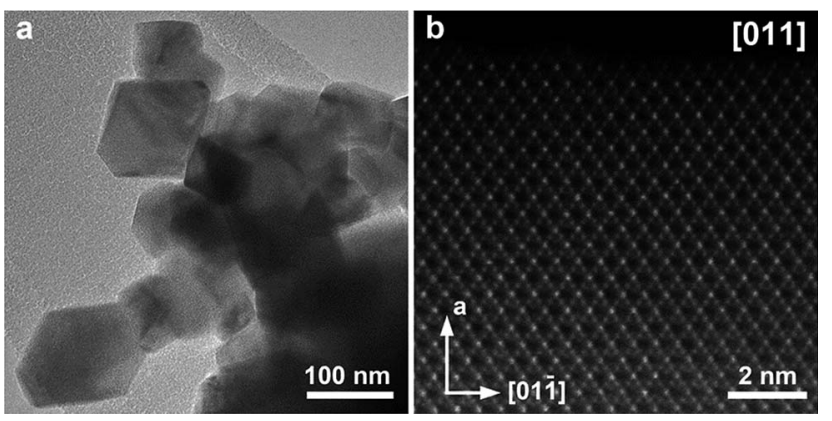

Fig. 11 TEM (a) and HAADF-STEM (b) images of $\mathrm{LiMnCoO}_{4}$ obtained by thermal decomposition of heterometallic precursor 1 a at $550{ }^{\circ} \mathrm{C}$.

heterobimetallic $\operatorname{LiMn}_{2}(\text { thd })_{5}$ molecules that have different volatilities, resulting in some loss of manganese upon thermal decomposition.

\section{Conclusion}

In accord with predictions of the theoretical calculations, it has been experimentally confirmed that in the parent trinuclear heterobimetallic molecule $\operatorname{LiMn}_{2}(\text { thd })_{5}$, only one of two manganese sites is sufficiently flexible to be substituted by cobalt. This results in an array of heterotrimetallic solid solutions up to the composition of $\mathrm{LiMnCo}(\mathrm{thd})_{5}$. In this research, we have concentrated on two stoichiometries for heterotrimetallic compounds: $\mathrm{Li}: \mathrm{Mn}: \mathrm{Co}=1: 1: 1$ (1a) and $1: 1.5: 0.5$ (1b). While the former was the major focus of investigation into making a "true" heterotrimetallic molecule, the latter was a specific target for prospective practical applications towards low-temperature preparation of the " $5 \mathrm{~V}$ spinel" cathode material $\mathrm{LiMn}_{1.5} \mathrm{Co}_{0.5} \mathrm{O}_{4}$.

This study is aligned with our recent quest for a design of heterotrimetallic molecular precursors that contain at least two transition metal atoms with close atomic numbers and radii. We have long stated that the construction of such molecules will ultimately require either different oxidation states for similar metal ions $\mathrm{s}^{3,58}$ or different coordination/ligand environment for the isovalent ones. The case reported here provides the first experimental demonstration that site-specific substitution is feasible in some polynuclear heterobimetallic assemblies that feature at least two metal sites with different (yet close) surroundings. This possibility emerges from the fact that one of two parent heterobimetallic molecules does not exist, which directly points to inability to substitute the parent metal atom in both positions.

Several instrumental methods have been found to be handy for deciphering the structure and composition of heterotrimetallic compounds. Synchrotron resonant diffraction experiments allow unambiguous assignment of $3 \mathrm{~d}$ transition metal positions as well as a precise "elemental analysis" for the $\mathrm{Mn}$ and Co content in a single crystal, even in such a difficult case of severely disordered heterometallic molecules. DART mass spectrometry proved to be the most efficient method to analyse the heteromultimetallic molecules. This relatively 
simple and fast analysis can be successfully executed when there is a sufficient structural integrity of the heterometallic ions in the gas phase as well as when the fragmentation/ recombination processes in mass spectrometer can be excluded.

The correct theoretical prediction of the substitution pattern in the parent heterobimetallic $\operatorname{LiMn}_{2}(\mathrm{thd})_{5}$ molecule is noteworthy as it opens a large window of opportunity to explore the design of other heterotrimetallic precursors of the general formula $\operatorname{LiMn}_{2-x} \mathbf{M}_{x}$ (thd) $)_{5}$. Of special importance are the systems with $\mathrm{M}=\mathrm{Mg}$ or $\mathrm{Ni}$, which represent single-source precursors for a very special class of spinel cathode materials for the Li-ion batteries..$^{22,25,59,60}$

\section{Conflicts of interest}

There are no conflicts of interest to declare.

\section{Acknowledgements}

Financial support from the National Science Foundation is gratefully acknowledged (CHE-1152441 for E. V. D. and CHE1464955 for M. S.). The authors thank the CRDF Global (FSCX-16-62133-0 for A. M. A.) and (OISE-16-62134-0 for E. V. D.) for funding this collaborative project. A. Yu R. is grateful for the financial support from the Illinois Institute of Technology and partial support from the 381688-FSU/ChemRing/DOD-DOTC grant. NSF's ChemMatCARS Sector 15 is principally supported by the Divisions of Chemistry (CHE) and Materials Research (DMR), National Science Foundation, under grant number NSF/ CHE-1346572. Use of the Advanced Photon Source, an Office of Science User Facility operated for the U.S. Department of Energy (DOE) Office of Science by Argonne National Laboratory, was supported by the U.S. DOE under Contract No. DE-AC0206CH11357. The authors also thank to Jeff Lengyel (Florida State University) for his assistance with the TGA.

\section{References}

1 P. Venkatesan and J. Santhanalakshmi, Langmuir, 2010, 26, 12225-12229.

2 H. Kuroki, T. Tamaki, M. Matsumoto, M. Arao, K. Kubobuchi, H. Imai and T. Yamaguchi, Ind. Eng. Chem. Res., 2016, 55, 11458-11466.

3 C. M. Lieberman, M. C. Barry, Z. Wei, A. Y. Rogachev, X. Wang, J.-L. Liu, R. Clérac, Y.-S. Chen, A. S. Filatov and E. V. Dikarev, Inorg. Chem., 2017, 56, 9574-9584.

4 V. R. Surisetty, A. K. Dalai and J. Kozinski, Ind. Eng. Chem. Res., 2010, 49, 6956-6963.

5 M. S. Whittingham, Chem. Rev., 2004, 104, 4271-4302.

6 N. Yabuuchi, K. Kubota, M. Dahbi and S. Komaba, Chem. Rev., 2014, 114, 11636-11682.

7 C. Yada, A. Ohmori, K. Ide, H. Yamasaki, T. Kato, T. Saito, F. Sagane and Y. Iriyama, Adv. Energy Mater., 2014, 4, 1301416.

8 J. S. Thorne, R. A. Dunlap and M. N. Obrovac, J. Electrochem. Soc., 2014, 161, A2232-A2236.
9 J. B. Goodenough, J. Power Sources, 2007, 174, 996-1000.

10 C. Masquelier, M. Tabuchi, K. Ado, R. Kanno, Y. Kobayashi, Y. Maki, O. Nakamura and J. B. Goodenough, J. Solid State Chem., 1996, 123, 255-266.

11 M. M. Thackeray, W. I. F. David, P. G. Bruce and J. B. Goodenough, Mater. Res. Bull., 1983, 18, 461-472.

12 A. M. Abakumov, A. A. Tsirlin, I. Bakaimi, G. Van Tendeloo and A. Lappas, Chem. Mater., 2014, 26, 3306-3315.

13 D. K. Kim, P. Muralidharan, H.-W. Lee, R. Ruffo, Y. Yang, C. K. Chan, H. Peng, R. A. Huggins and Y. Cui, Nano Lett., 2008, 8, 3948-3952.

14 J. Molenda, M. Ziemnicki, J. Marzec, W. Zając, M. Molenda and M. Bucko, J. Power Sources, 2007, 173, 707-711.

15 G. Rousse, C. Masquelier, J. Rodríguez-Carvajal, E. Elkaim, J. P. Lauriat and J. L. Martínez, Chem. Mater., 1999, 11, 3629-3635.

16 M. M. Thackeray, P. J. Johnson, L. A. de Picciotto, P. G. Bruce and J. B. Goodenough, Mater. Res. Bull., 1984, 19, 179-187.

17 R. J. Gummow, A. de Kock and M. M. Thackeray, Solid State Ionics, 1994, 69, 59-67.

18 T. Takada, H. Hayakawa and E. Akiba, J. Solid State Chem., 1995, 115, 420-426.

19 A. Kraytsberg and Y. Ein-Eli, Adv. Energy Mater., 2012, 2, 922939.

20 C. Lai, J. Chen, J. C. Knight, A. Manthiram and A. Navrotsky, ChemPhysChem, 2016, 17, 1942.

21 H.-C. Wang and C.-H. Lu, J. Power Sources, 2003, 119-121, 738-742.

22 P. Strobel, J. Tillier, A. Diaz, A. Ibarra-Palos, F. Thiery and J. B. Soupart, J. Power Sources, 2007, 174, 910-915.

23 P. Strobel, A. Ibarra-Palos, M. Anne, C. Poinsignon and A. Crisci, Solid State Sci., 2003, 5, 1009-1018.

24 P. Strobel, A. Ibarra-Palos and C. Poinsignon, Mater. Res. Soc. Symp. Proc., 2003, 756, 225-230.

25 P. Strobel, A. Ibarra Palos, M. Anne and F. Le Cras, J. Mater. Chem., 2000, 10, 429-436.

26 S. L. Zhao, H. Y. Chen, J. B. Wen and D. X. Li, J. Alloys Compd., 2009, 474, 473-476.

27 K. Dokko, N. Anzue, M. Mohamedi, T. Itoh and I. Uchida, Electrochem. Commun., 2004, 6, 384-388.

28 A. D. Robertson, A. R. Armstrong and P. G. Bruce, J. Power Sources, 2001, 97-98, 332-335.

29 M.-s. Zhao, F. Wang and X.-p. Song, Zhongguo Youse Jinshu Xuebao, 2005, 15, 1396-1402.

30 Z. Wang, H. Ikuta, Y. Uchimoto and M. Wakihara, J. Electrochem. Soc., 2003, 150, A1250-A1254.

31 K. Mukai and T. Uyama, ACS Omega, 2017, 2, 5142-5149.

32 K. Park, D. Yeon, J. H. Kim, J.-H. Park, S. Doo and B. Choi, J. Power Sources, 2017, 360, 453-459.

33 P. K. Nayak, E. M. Erickson, F. Schipper, T. R. Penki, N. Munichandraiah, P. Adelhelm, H. Sclar, F. Amalraj, B. Markovsky and D. Aurbach, Adv. Energy Mater., 2017, 8, 1702397.

34 F. Zhou, M. Cococcioni, K. Kang and G. Ceder, Electrochem. Commun., 2004, 6, 1144-1148.

35 P. T. Barton, Y. D. Premchand, P. A. Chater, R. Seshadri and M. J. Rosseinsky, Chem.-Eur. J., 2013, 19, 14521-14531. 
36 Y.-K. Sun, I.-H. Oh and K. Yul Kim, J. Mater. Chem., 1997, 7, 1481-1485.

37 B. Mortemard de Boisse, PhD thesis, Université de Bordeaux, 2014.

38 B. Mortemard de Boisse, D. Carlier, M. Guignard and C. Delmas, J. Electrochem. Soc., 2013, 160, A569-A574.

39 M. V. Reddy, G. V. S. Rao and B. V. R. Chowdari, J. Phys. Chem. C, 2007, 111, 11712-11720.

40 M. J. Ariza, D. J. Jones, J. Rozière, R. Chitrakar and K. Ooi, Chem. Mater., 2006, 18, 1885-1890.

41 M. M. Thackeray, M. F. Mansuetto and C. S. Johnson, J. Solid State Chem., 1996, 125, 274-277.

42 M. M. Thackeray, M. F. Mansuetto, D. W. Dees and D. R. Vissers, Mater. Res. Bull., 1996, 31, 133-140.

43 S.-T. Myung, K. Amine and Y.-K. Sun, J. Power Sources, 2015, 283, 219-236.

44 T. Takada, H. Hayakawa, E. Akiba, F. Izumi and B. C. Chakoumakos, J. Power Sources, 1997, 68, 613-617.

45 S.-J. Kim, Y.-W. Lee, B.-M. Hwang, S.-B. Kim, W.-S. Kim, G. Cao and K.-W. Park, RSC Adv., 2014, 4, 11598-11604.

46 M. Bianchini, E. Suard, L. Croguennec and C. Masquelier, J. Phys. Chem. C, 2014, 118, 25947-25955.

47 Y. Gao and J. R. Dahn, J. Electrochem. Soc., 1996, 143, 17831788.

48 M. M. Thackeray, Prog. Solid State Chem., 1997, 25, 1-71.

49 H. Han, Z. Wei, M. C. Barry, A. S. Filatov and E. V. Dikarev, Dalton Trans., 2017, 46, 5644-5649.
50 K. M. Fleming, J. C. Pekar and B. D. Leskiw, Rapid Commun. Mass Spectrom., 2016, 30, 2423-2432.

51 A. Navulla, L. Huynh, Z. Wei, A. S. Filatov and E. V. Dikarev, J. Am. Chem. Soc., 2012, 134, 5762-5765.

52 Z. Wei, H. Han, A. S. Filatov and E. V. Dikarev, Chem. Sci., 2014, 5, 813-818.

53 C. Julien, C. Letranchant, S. Rangan, M. Lemal, S. Ziolkiewicz, S. Castro-Garcia, L. El-Farh and M. Benkaddour, Mater. Sci. Eng., B, 2000, 76, 145-155.

54 H. Han, Z. Wei, M. C. Barry, J. C. Carozza, M. Alkan, A. Yu. Rogachev, A. S. Filatov, A. M. Abakumov and E. V. Dikarev, Chem. Sci., 2018, 9, 4736-4745.

55 M. C. Barry, C. M. Lieberman, Z. Wei, R. Clérac, A. S. Filatov and E. V. Dikarev, Inorg. Chem., 2018, 57, 2308-2313.

56 J. C. Knight, S. Therese and A. Manthiram, J. Electrochem. Soc., 2015, 162, A426-A431.

57 H. Berg and J. O. Thomas, Solid State Ionics, 1999, 126, 227234.

58 C. M. Lieberman, A. S. Filatov, Z. Wei, A. Yu. Rogachev, A. M. Abakumov and E. V. Dikarev, Chem. Sci., 2015, 6, 2835-2842.

59 H. Kobayashi, Y. Arachi, H. Kageyama and K. Tatsumi, J. Mater. Chem., 2004, 14, 40-42.

60 C. Johnson, A. Gutierrez, P. Senguttuvan, S. Lapidus, S. Kim and T. T. Fister, ECS Meeting Abstracts, 2016, vol. MA2016-03, p. 1098. 